\title{
Design and Optimization of an Eddy Current Speed Sensor for Rotating Rods
}

\author{
Mehran Mirzaei, Pavel Ripka, Vaclav Grim, and Andrey Chirtsov
}

\begin{abstract}
This paper presents the design and optimization of a novel eddy current speed sensor for rotating rods and cylindrical shafts. The sensor consists of one excitation coil and two pick-up coils. All coils are stationary; we consider air coils, and we also use a magnetic yoke. We utilize a copper coating on an iron rod to increase the sensitivity, and we compare the performance with the performance achieved for an uncoated iron rod. 3D FEM is utilized for analyzing and for optimizing the design of the proposed sensor. The main advantages of the novel sensors are their simplicity, their low cost and their robust configuration. A line arity error of $0.5 \% \mathrm{~h}$ as been achieved. The level of accu racy is limited by mechanical factors. A 1D analytical model has also been developed for rapid analysis and optimization of the sensor. An aluminum rod was also used in the measurements for a comparison with the results achieved with the iron rod.
\end{abstract}

Index Terms - Eddy current speed sensor, optimization, copper coating, steel lamination, rotating rods, 3D FEM.

\section{INTRODUCTION}

$\mathrm{T}$ HE electrification of transportation, e.g., electric cars, railways and airplanes, and also the renewable energies are continuously increasing, and this es pecially involves replacing rotating mechanical elements with their electrical counterparts. Traction motors, electrically-assisted turbo chargers and other rotating elements need speed sensing for control purposes, and for diagnosing and preventing mechanical and electrical faults [1]-[8]. The simplicity of the sensor is of no less importance than its precision. Speed and position sensors often need compensation of mechanical issues, e.g., lift off and eccentricity. It is therefore a key advantage to use a sensor with a simple design for speed meas urements.

Sensorless speed measurement methods for rotating electrical machines are well developed, although their signal processing is complex and time-consuming, and may not be rapid enough for control purposes [9]-[10]. Optical sens ors are also widely used for speed measurements, but they may not be appropriate for harsh and dusty environments, and they often need maintenance to clean out dust and dirt [11]. The use of an external magnetic field sensor mounted on the housing of a machine was presented in [12]. Since it is not non-destructive, it needs magnetic shielding against external magnetic fields. Implementing a Hall sensor in the stator or inside the end windings to measure the speed of the rotating rotor was

This work was supported in part by the Czech Technical University in Prague under Grant SGS18/187/OHK3/3T/1.

M. Mirzaei is with the Faculty of Electrical Engineering, Czech Technical University, Prague 16627, Czech Republic (e-mail: mirzameh@fel.cvut.cz).

P. Ripka is with the Faculty of Electrical Engineering, Czech Technical University, Prague 16627, Czech Republic (e-mail: ripka@fel.cvut.cz). presented in [13]-[14]. However, this may be unreliable, e. g. in conditions where the winding becomes overheated. Variable reluctance (VR) or saliency-based speed measurements with pick-up coils or Hall sensors have als o been used in industry for rotating machines. However, a non-salient magnetic surface needs to be built for operating reluctance variations or for changing the induced eddy current [15]-[18]. Recent works us ing electrostatic phenomena to measure speed were published in [19]-[20]. However, these sensors will be quite sensitive to dirt and dust, and they therefore need to be capsulated.

There is a long history in electrical engineering of utilizing the speed component of an induced eddy current, going back to the Faraday generator and the unipolar generator. The eddy current brake is another use of the speed component of the eddy current [21]-[22]. A non-destructive testing method for metals utilizes the same principle, as has been reported in [23]-[24].

Magnetic flow meters are used to measure the speed of fluids by reading the voltage caused by speed effects with electrodes in contact with the fluid across the fluid flowing in magnetic fields perpendicular to the direction of the flowing fluid [11] and [25]. A speed sensor using the fluxgate effect in an amorphous ring core to measure the field of eddy currents was presented in [26]. This rather complicated sensor has a poor linearity error of approx. 5\%. A rotating permanent magnet rotor for contactless eddy current speed sensing was tested and analyzed in [27]; this type of sensor is not easy to manufacture and use because of the moving part. A Hall sensor with permanent magnet excitation was presented in [28]; however, this sensor shows poor offset stability.

Parallel and perpendicular types of eddy current-based speed sensors with air coils for excitation and pick-up voltage were analyzed and measured in detail in [24] and in [29]-[33]. The same parallel configuration as in [33], with one excitation coil and two pick-up coils using a ferrite magnetic yoke, was measured in [34]. These sensors use only aluminum for the moving part, though iron is a material typically used for shafts. The authors recently investigated linear speed sensors for variable speeds and a rotational speed sensor for constant speeds, using solid irons and steels for the moving part, taking into account the effects of the materials of the moving parts on the performance of the eddy current speed sensor [35]-[37].

Our new eddy current speed sen sor for measuring the speed of rotating ferromagnetic bodies is based on an optimized single

V. Grim is with the Faculty of Electrical Engineering, Czech Technical University, Prague 16627, Czech Republic (e-mail: vaclav.grim@fel.cvut.cz).

A. Chirtsov is with the Faculty of Electrical Engineering, Czech Technical University, Prague 16627, Czech Republic (e-mail: chirtand@fel.cvut.cz). 
excitation coil with an AC current and two pick-up coils for measurements without magnetic yoke. This sens or has high sensitivity with the air coils configuration. The time stepping 3D finite element method (FEM) simulation, taking into account the speed of the rotating part, is also presented for a comparis on with measurements that could be used to es timate and optimize the performance of the eddy current speed sensor. A one-dimensional analytical model has also been developed and utilized for optimizing the design of eddy current speed sens ors. A copper coating, which provides increased sensitivity, is applied to the rotating iron rod. A study of the magnetic shield and the magnetic yoke for the eddy current speed sensor, using various thicknesses and magnetic materials for the shield, is also presented in this paper.

\section{Model ANd Performance}

Fig. 1 shows the configuration and the structure of the proposed eddy current speed sensor with an air core structure for a rotating conductive rod. The total coils span is $360 \mathrm{Deg}$., in order provide increased sensitivity. One excitation coil and two antiserially connected pick-up coils are used.

The magnetic flux linkages of the pick-up coils diverge from each other if the rotating rod speed is nonzero (Fig. 2). The difference in flux linkage between the left side and the rightside pick-up coils is proportional to the speed of the rotating conductive rod, and it can be measured in the case of AC current for the excitation coil as the differential induced voltage.

A simplified 1D analytical model is developed in appendix A for general analysis and for fast optimization of an eddy current speed sensor for rotating bodies (Fig. A1 (a)). The total angle span of the excitation coil and the pick-up coils covers the whole 360 deg. range, in order to achieve maximum sensitivity for the sensor $\left(\theta_{\mathrm{p} 1}=\theta_{\mathrm{e}}, \theta_{\mathrm{p} 2}=180\right.$ Deg. in Fig. A1 (a)). Fig. 3 (a) shows that the optimum excitation coil angle span, $2 \theta_{\mathrm{e}}$, is 120 Deg. in order to obtain the maximum voltage difference between the pick-up coil voltages. However, the maximum pick-up coil voltage values are obtained when the excitation coil angle span, $2 \theta_{\mathrm{e}}$, is $180 \mathrm{Deg}$.

The induced eddy current in the rotating rod weakens the magnetic fields under the excitation coil and the pick-up coils, as shown in Fig. 4. The rotating rod speed effect causes the as ymmetric distribution of the magnetic fields shown in Fig. 4, which causes the different flux linkage and different induced voltage in the two pick-up coils (Fig. 3 (a)).

Fig. 3 (b) presents a linear curve for the real, imaginary and absolute components of the differential voltage (relative to the excitation coil current as a reference signal) versus speed, which can be utilized as a speed meter. The phase (the "polarity") of the induced voltage in the pick-up coils changes as the speed direction changes. The excitation current amplitude is considered constant at different speeds and frequencies in all simulations in this paper.
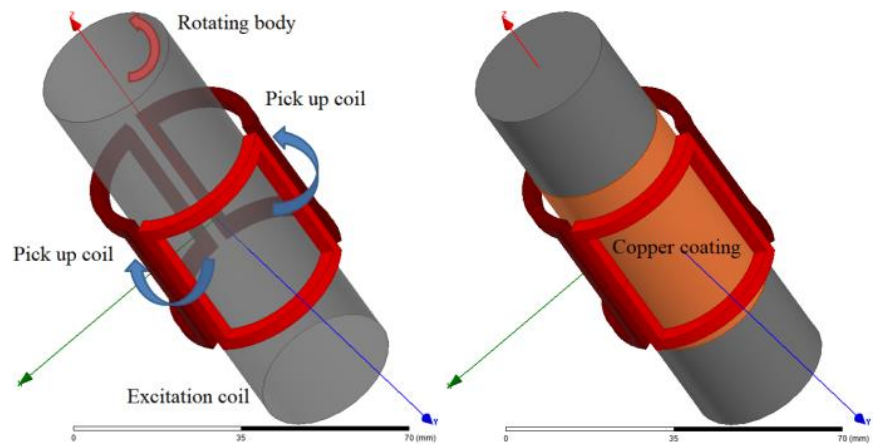

Fig. 1. 3D model of an eddy current speed sensor, a) a rotating rod with only a solid iron rod (left), and b) a rotating rod with a solid iron rod coated with a copper layer (right)
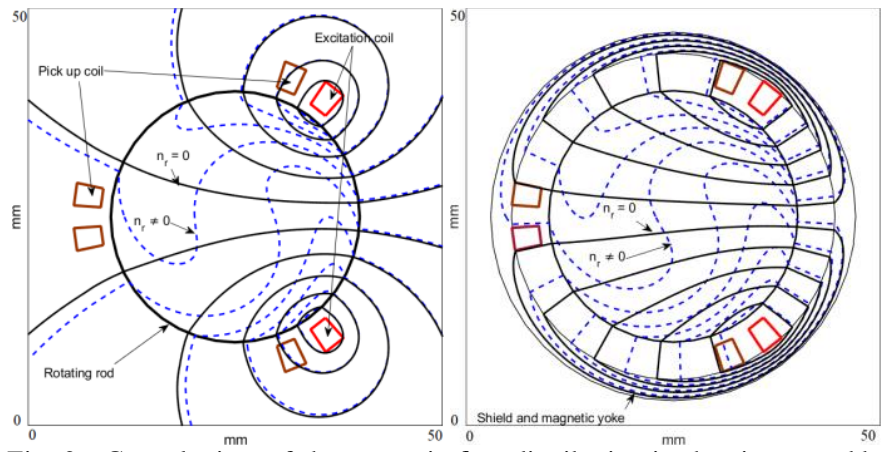

Fig. 2. General view of the magnetic flux distribution in the air core eddy current speed sensor a) without shield (left) and b) with shield and magnetic yoke (right)
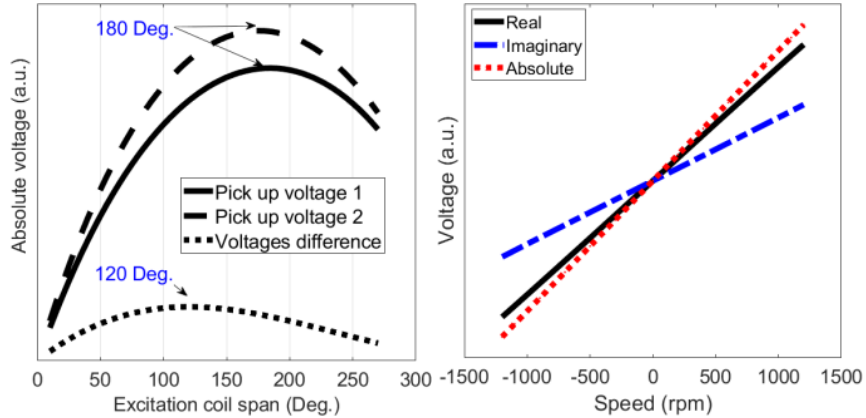

Fig. 3. a) Pick-up coil voltages and their voltage difference versus the excitation coil span (left) b) differential voltage variations versus rotating rod speed (right) - values calculated by the simplified 1D analytical model described in Appendix A

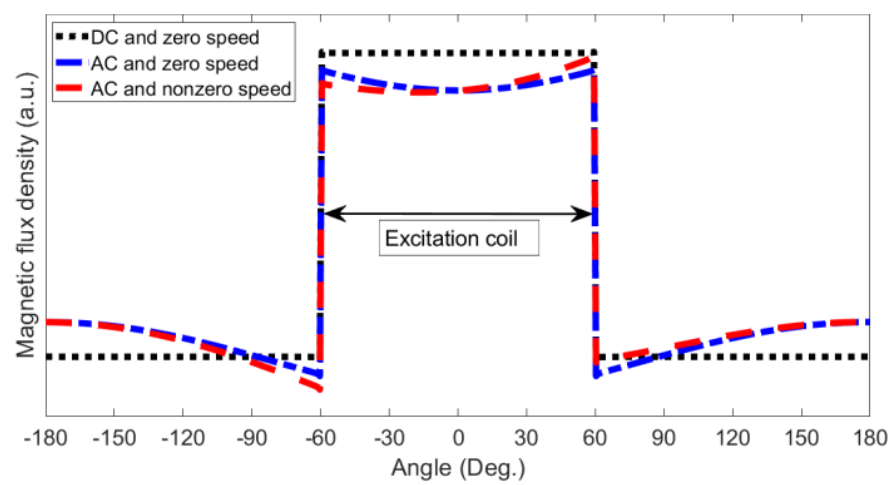

Fig. 4. Variations in magnetic flux density under an excitation coil and pick-up coils - the dotted line is for DC and zero speed, the dot-dashed line is for AC and zero speed, and the dashed line is for $\mathrm{AC}$ and nonzero speed. Values calculated by the simplified 1D analytical model described in Appendix A 
The excitation and pick up coils have smaller area in the the case of rotating rod compared to similar linear speed sensor [35] and also equivalent linear speed is rather low: for example, with $3 \mathrm{~cm}$ diameter and the surface linear speed of the rotating rod at $1200 \mathrm{rpm}$ is less than $2 \mathrm{~m} / \mathrm{s}$. Therefore, the sensitivity of speed sens or for rotating rod is low for low speeds and it is more difficult to measure rotating speed in comparison with linear speeds.

\section{EXPERIMENT AL RESULTS}

Fig. 5 and Fig. 6 show the experimental element, the eddy current speed sensor element, measurement instruments and schematic block diagram for speed measurements. A Keithley 3390 signal generator with amplitude accuracy $1 \%$ of setting and internal resistance of $50 \Omega$ is used to supply the excitation coil, . A lock-in amplifier SR 830 with gain accuracy $\pm 1 \%$ is utilized for the voltage measurements, in order to measure the voltage of the pick-up coils with minimum noise effects. The full scale sensitivity is $2 \mathrm{nV}$ to $10 \mathrm{~V}$.

Iron rods $100 \mathrm{~mm}$ and $200 \mathrm{~mm}$ in axial length are used for the measurements (Fig. 5), which showed a negligible effect of the axial length on the sensitivity of the speed sensor. The outer diameter of the iron rod is $30 \mathrm{~mm}$, the inner diameter of the coils is $33.5 \mathrm{~mm}$, and the outerdiameter of the coils is $39.5 \mathrm{~mm}$. All three coils are identical and have 100 turns per coil. The rods are connected to the shaft of the DC motor as the prime mover in the test bench. The measured speed range is between $1200 \mathrm{rpm}$ and $+1200 \mathrm{rpm}$.

Fig. 7 and Fig. 8 show the measured differential voltages of the eddy current speed sensor versus the speed only for the iron rod and for the iron rod with a copper coating, at $120 \mathrm{~Hz}$ and at $180 \mathrm{~Hz}$. The real $\left(U_{\mathrm{r}}\right)$, imaginary $\left(U_{\mathrm{i}}\right)$ and absolute $\left(U_{a}\right)$ components of the differential voltage are presented:

(1)

$$
U_{a}=\sqrt{U_{r}^{2}+U_{i}^{2}}
$$

The applied current in the excitation coil is considered as the reference signal for calculating the real (Re) and imaginary (Im) components of the differential voltage. The polarity of the absolute values of the induced (differential) voltage is calculated using the phase shift between the induced voltage and the excitation coil current. Table I presents the linear curve parameters (induced voltage $U$, constant $K$, and speed $S$, using (2) fitted to the measurements in Fig. 7 and Fig. 8). The offset values for the voltage ( $U_{\text {offset }}$ ) are removed numerically in the absolute values of the induced voltage in Figs. 7 and 8 .

$$
U=K \cdot S+U_{\text {offset }}
$$

TABLE I

Linear CuRve Parameters Fitted to The MEasurements

\begin{tabular}{ccc}
\hline \hline Case & $K(n \mathrm{~V} / \mathrm{rpm})$ & $U_{\text {offset }}(\mu \mathrm{V})$ \\
& $120 \mathrm{~Hz} / 180 \mathrm{~Hz}$ & $120 \mathrm{~Hz} / 180 \mathrm{~Hz}$ \\
\hline Only iron - Re & $110.92 / 133.38$ & $13275 / 22417$ \\
Only iron - Im & $73.09 / 79.86$ & $-32687 /-54542$ \\
Only iron - Abs & $132.85 / 155.47$ & 0 \\
With copper - Re & $152.68 / 204.98$ & $15333 / 29646$
\end{tabular}

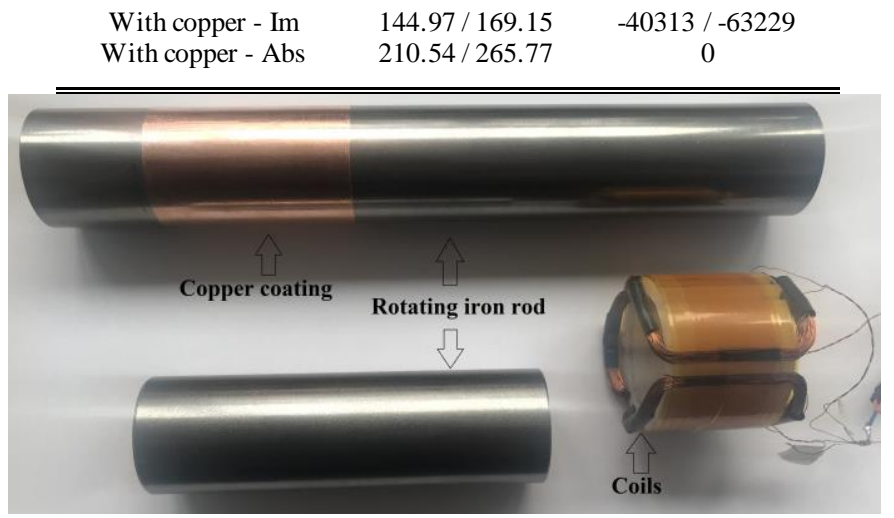

Fig. 5. Rotating solid iron rods with a thin copper layer and the coils of an eddy current speed sensor
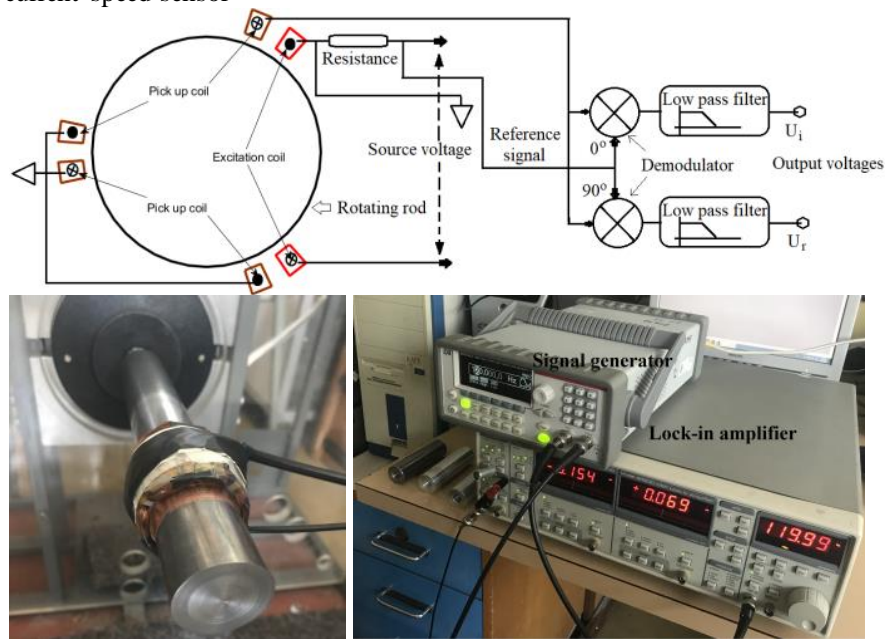

Fig. 6. a) Schematic block diagram for speed measurement (top) and b) a eddy current speed sensor mounted on the rotating solid iron rod and a signal generator and a lock-in amplifier (bottom)
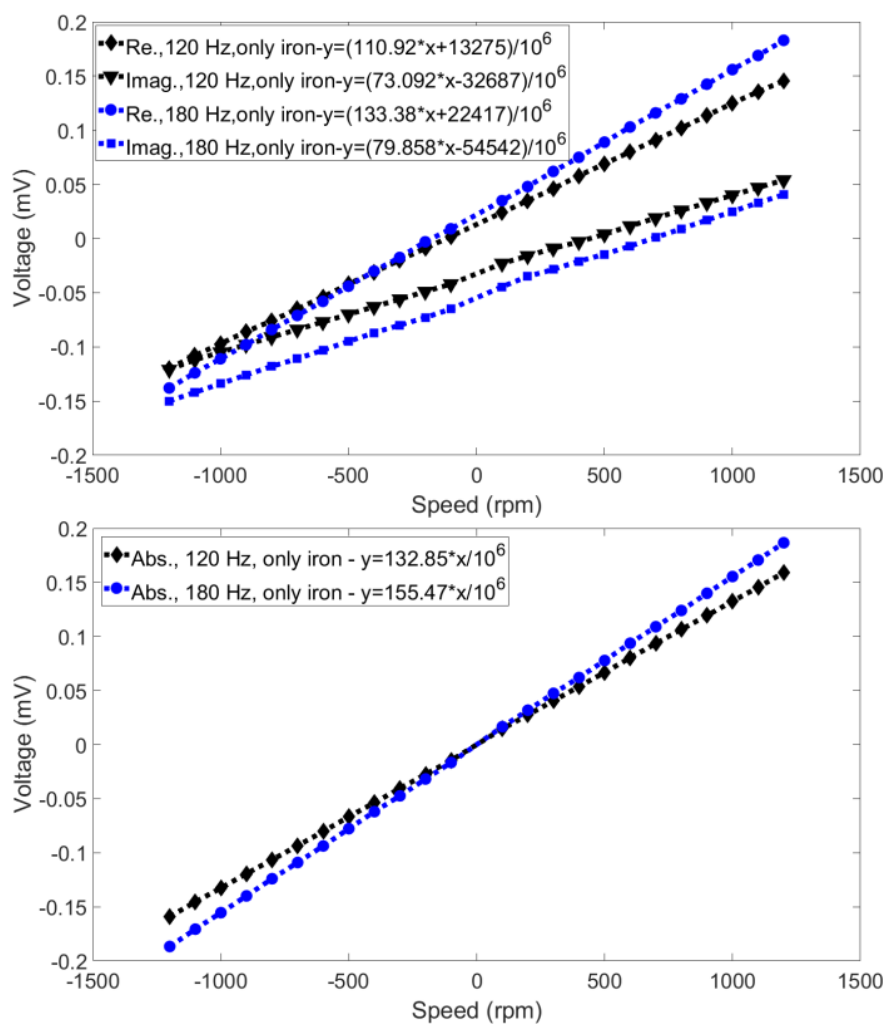
Fig. 7. Differential induced voltage (rms) caused by speed of the rotating rod for only a solid iron rod, a) for the real and imaginary components of the voltage (top), and b) the absolute value of the voltage (bottom) - experimental results

The offset values are mainly cau sed by eccentricity, by prime mover or motor vibrations and the slightly asymmetric positions of pick-up coils with a different magnetic coupling between the excitation coil and the pick-up coils. These offset values can easily be minimized by providing a more precise mechanical set-up. It is shown that the offset values are lower in the real component than in the imaginary component of the induced voltage, as the imaginary component is proportional to the magnetic gap, $(g \pm \Delta g)$, and the real component is not roughly proportional to $(g \pm \Delta g)$ according to (A8). Any fractional change in magnetic gap $\Delta g$ can have a greater influence on the imaginary component of the induced voltage. The sensitivity of the eddy current speed s ensor is higher for the real component of the induced voltage than for the imaginary component of the induced voltage.

Increasing the excitation frequency from $120 \mathrm{~Hz}$ to $180 \mathrm{~Hz}$ improves the sensitivity of the eddy current speed sensor by about $17.4 \%$ in the only iron rod and by $26.2 \%$ in the coppercoated iron rod for absolute values of the induced voltages. The copper coating is $70 \mu \mathrm{m}$ in thicknes s and $50 \mathrm{~mm}$ in height, see the measured results in Fig. 8. When a copper coating is used for the abs olute values of the induced voltages, the sen sitivities increase by $59 \%$ at $120 \mathrm{~Hz}$, and by $71 \%$ at $180 \mathrm{~Hz}$, in comparis on with the only iron rod.

The amplitude of current in the excitation coil is $150 \mathrm{~mA}$ in all measurements. The influence of the excitation coil reactance on the excitation coil current is negligible because air coil inductance is small.

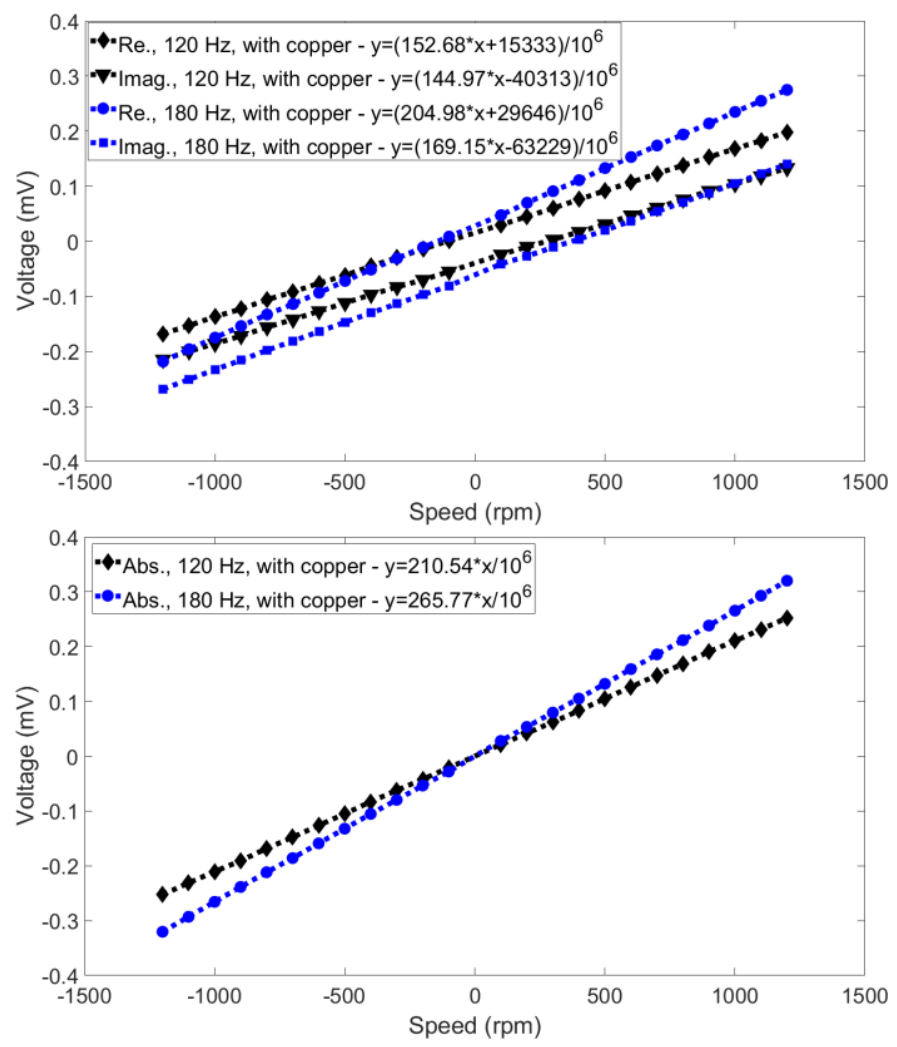

Fig. 8. Differential induced voltage (rms) caused by the speed of the rotating rod for a copper-coated solid iron rod, a) real and imaginary components of the voltage (top), and b) absolute value of the voltage (bottom)) - experimental results

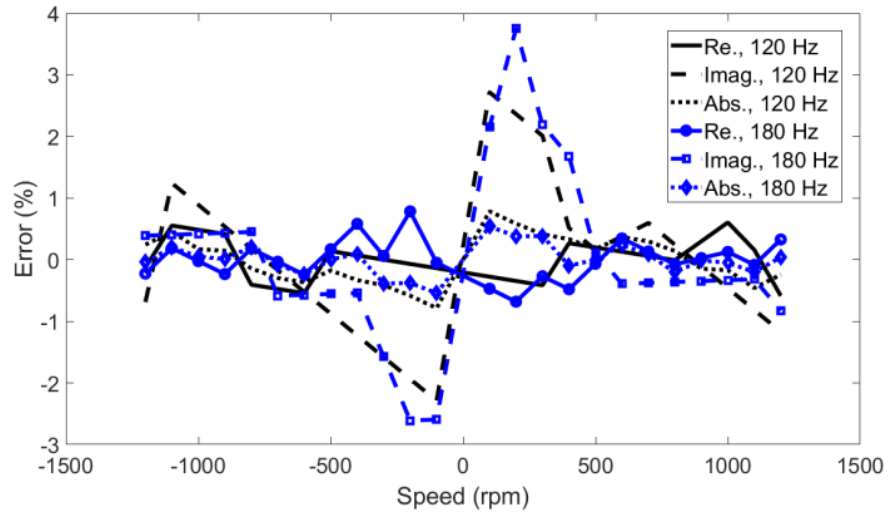

Fig. 9. Measured linearity errors for the only solid iron rod

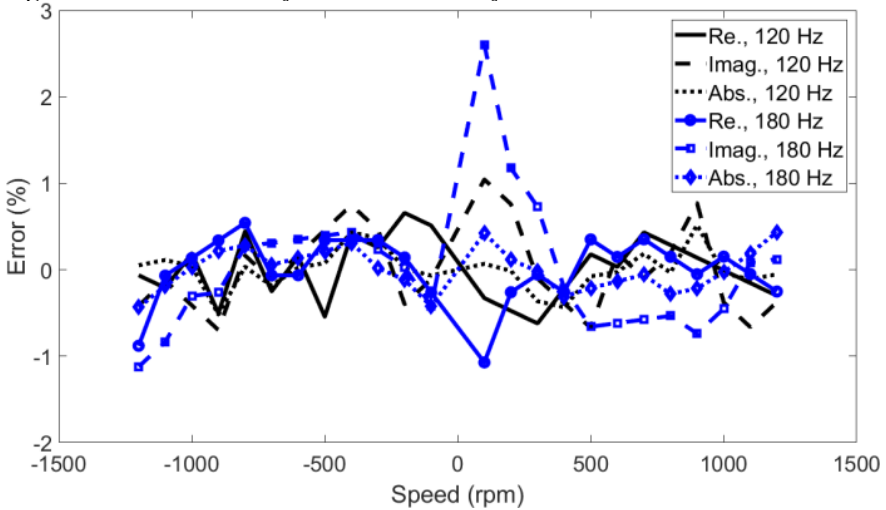

Fig. 10. Measured linearity errors for the copper-coated solid iron rod

The linearity error curves versus speed for different components of the induced voltage are shown in Fig. 9 and Fig. 10 using the linear curve fit parameters in Table I. The maximum error is about $0.5 \%$ except at low speeds for imaginary components of theinduced voltage. The peaks in the error curves for the imaginary component are mainly caused by vibration of the motor s haft or by the external res onance effect at low speeds, which can be avoided in a better experimental set-up. Similar reasons as for the higher offset errors can provide an explanation for the higher linearity errors for the imaginary component of the induced voltage, due to higher dependency on the magnetic gap variations and eccentricity.

\section{FEM ANALYSIS}

Only linear magnetic modeling using the initial permeability is considered here. Due to the low magnetic fields in the sensor, nonlinearity effects and hysteresis effects are neglected. The first es timate for the relative magnetic permeability of the iron rod is $\mu_{\mathrm{r}-\mathrm{i}}=100$, and this value was us ed in the simulations. The electrical conductivity is measured as $\sigma_{\mathrm{i}}=5.54 \mathrm{MS} / \mathrm{m}$ for the iron rod. The eddy current distributions in the half model of the speed sensor are depicted in Fig. 11 using time-stepping 3D FEM. The current amplitude is considered $150 \mathrm{~mA}$ in all simulations equal to the measured value.

Tables II and III show a comparis on between the 3D FEM results and the experimental results for the only iron rod and for the copper-coated iron rod. The 3D FEM results coincide better 
with the measurements in the copper-coated iron rod than with the measurements in the only iron rod. This is because the permeability of the iron rod plays a less important role in the performance of the eddy current speed sensor. Table IV presents the effects of the permeability of the iron rod on the sensitivity of the eddy current speed sensor, confirming that it has a greater influence on the only iron rod. Lower relative magnetic permeability cau ses higher sensitivity because of the greater magnetic fluxpenetration depth and larger skin depth.

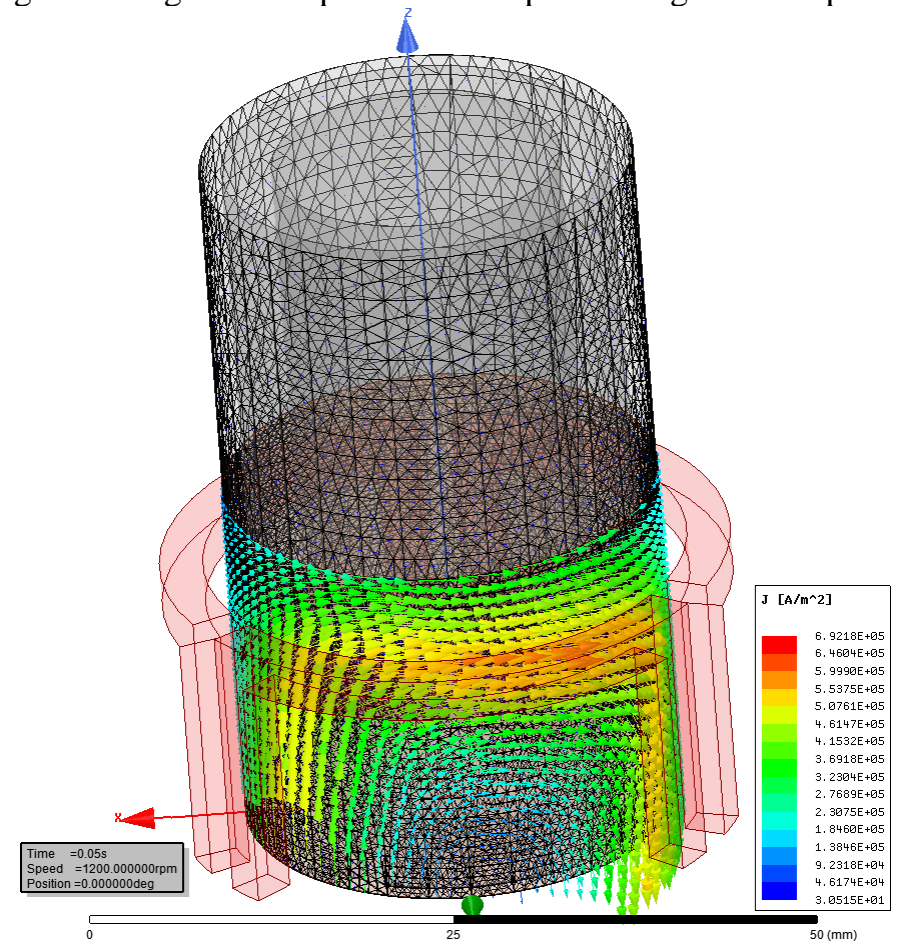

Fig. 11. Eddy current distribution in the copper-coated iron rod at $120 \mathrm{~Hz}$ and $1200 \mathrm{rpm}$
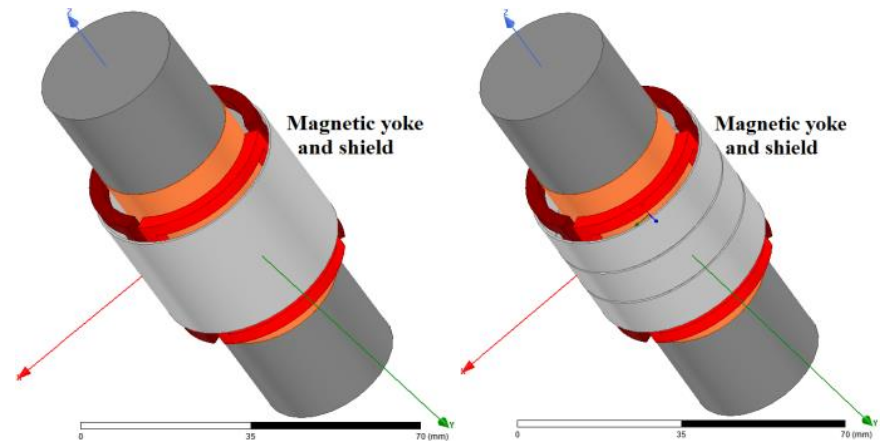

Fig. 12. A magnetic yoke and a shield in the eddy current speed sensor - shield height $=30 \mathrm{~mm}$

TABLE II

A COMPARISON BETWEEN MEASUREMENTS AND 3D FEM - ONLY IRON AND WITHOUT A SHIELD

\begin{tabular}{ccc}
\hline \hline & $120 \mathrm{~Hz}$ & $180 \mathrm{~Hz}$ \\
& 3D FEM / Exp. & 3D FEM / Exp. \\
\hline $300 \mathrm{rpm}$ & $34.5 / 40.5 \mu \mathrm{V}$ & $39.8 / 47.4 \mu \mathrm{V}$ \\
$600 \mathrm{rpm}$ & $71.1 / 80.3 \mu \mathrm{V}$ & $80.6 / 93.7 \mu \mathrm{V}$ \\
$1200 \mathrm{rpm}$ & $144.8 / 159.0 \mu \mathrm{V}$ & $169.7 / 186.6 \mu \mathrm{V}$ \\
\hline \hline
\end{tabular}

TABLE III

A COMPARISON BETWEEN MEASUREMENTS AND 3D FEM - WitH COPPER AND WITHOUT A SHIELD

\begin{tabular}{ccc}
\hline \hline & $120 \mathrm{~Hz}$ & $180 \mathrm{~Hz}$ \\
& 3D FEM / Exp. & 3D FEM / Exp. \\
\hline $300 \mathrm{rpm}$ & $61.5 / 62.2 \mu \mathrm{V}$ & $80.0 / 79.7 \mu \mathrm{V}$ \\
$600 \mathrm{rpm}$ & $126.3 / 126.3 \mu \mathrm{V}$ & $160.5 / 159.0 \mu \mathrm{V}$ \\
$1200 \mathrm{rpm}$ & $255.4 / 252.5 \mu \mathrm{V}$ & $324.6 / 320.3 \mu \mathrm{V}$ \\
\hline \hline
\end{tabular}

The higher electrical conductivity of the iron rod increases the sensor output voltage (Table V).

TABLE IV

3D FEM - WITHOUT A SHIELD

\begin{tabular}{|c|c|c|}
\hline $\begin{array}{l}120 \mathrm{~Hz} \text { and } \\
1200 \mathrm{rpm}\end{array}$ & Only Iron & With copper \\
\hline$\mu_{\mathrm{r}-\mathrm{i}}=75$ & $163.7 \mu \mathrm{V}$ & $271.2 \mu \mathrm{V}$ \\
\hline$\mu_{\mathrm{r}-\mathrm{i}}=100$ & $144.8 \mu \mathrm{V}$ & $255.4 \mu \mathrm{V}$ \\
\hline$\mu_{\mathrm{r}-\mathrm{i}}=125$ & $131.4 \mu \mathrm{V}$ & $245.2 \mu \mathrm{V}$ \\
\hline \multicolumn{3}{|c|}{$\begin{array}{c}\text { TABLE V } \\
\text { 3D FEM - WITHOUT A SHIELD } \\
\end{array}$} \\
\hline $\begin{array}{c}120 \mathrm{~Hz} \text { and } \\
1200 \mathrm{rpm}, \mu_{\mathrm{r}-\mathrm{i}}=100\end{array}$ & Only Iron & With copper \\
\hline$\sigma_{\mathrm{i}}=4.0 \mathrm{MS} / \mathrm{m}$ & $127.9 \mu \mathrm{V}$ & $244.3 \mu \mathrm{V}$ \\
\hline$\sigma_{\mathrm{i}}=5.0 \mathrm{MS} / \mathrm{m}$ & $139.3 \mu \mathrm{V}$ & $251.9 \mu \mathrm{V}$ \\
\hline$\sigma_{\mathrm{i}}=5.54 \mathrm{MS} / \mathrm{m}$ & $144.8 \mu \mathrm{V}$ & $255.4 \mu \mathrm{V}$ \\
\hline
\end{tabular}

A magnetic shield/yoke is used to increase the sensitivity and to shield the sensor from external interference (Fig. 2 b)). Magnetic shield made of high permeability ferromagnetic material such as steel lamination, permalloy sheet or Ferrite core [11] is surrounding magnetic sensor. . External field can not get into magnetic sensor due to the shielding effect. The shield yoke also concentrates and amplifies working magnetic field of the sensors. Fig. 12 shows the configurations of the magnetic yoke/shields. Tables VI - IX present the results with magnetic shields. The magnetic shield $(0.5 \mathrm{~mm}$ in thickness with $\mu_{\mathrm{r}-\mathrm{s}}=1000$ ) increases the sensitivity by about $700 \%$ (Table VI).

The variations in the sensitivity of an eddy current speed sensor versus the magnetic permeability of a solid iron rod are lower for sensors with a magnetic shield (Table VIII) than for sensors without a magnetic shield (Table IV). Approaches aimed at compensating and minimizing the effect of the permeability of the iron rod on the performance of the sensor should simultaneously u se a thick enough copper coating and a magnetic shield.

The use of high permeability thin permalloy sheets could significantly increase the output of the sensor, as shown in Table IX. The use of a thinner permalloy sheet also helps for compactness, and for an eas y and cost-effective manufacturing process for the eddy current speed sensor.

TABLE VI

3D FEM - ONLY IRON AND WITH A SHIELD

\begin{tabular}{ccc}
\hline \hline \multirow{2}{*}{$0.5 \mathrm{~mm}, \mu_{\mathrm{r}-\mathrm{s}}=1000$} & $120 \mathrm{~Hz}$ & $180 \mathrm{~Hz}$ \\
& $3 \mathrm{D} \mathrm{FEM}$ & $3 \mathrm{D} \mathrm{FEM}$ \\
\hline $300 \mathrm{rpm}$ & $262.3 \mu \mathrm{V}$ & $293.8 \mu \mathrm{V}$ \\
$600 \mathrm{rpm}$ & $530.3 \mu \mathrm{V}$ & $585.5 \mu \mathrm{V}$ \\
$1200 \mathrm{rpm}$ & $1070.6 \mu \mathrm{V}$ & $1204.9 \mu \mathrm{V}$ \\
\hline \hline
\end{tabular}


3D FEM - WITH COPPER AND WITH A SHIELD

\begin{tabular}{|c|c|c|}
\hline $0.5 \mathrm{~mm}, \mu_{\mathrm{r}-\mathrm{s}}=1000$ & $\begin{array}{c}120 \mathrm{~Hz} \\
3 \mathrm{D} \mathrm{FEM}\end{array}$ & $\begin{array}{c}180 \mathrm{~Hz} \\
\text { 3D FEM }\end{array}$ \\
\hline $\begin{array}{l}300 \mathrm{rpm} \\
600 \mathrm{rpm} \\
1200 \mathrm{rpm}\end{array}$ & $\begin{array}{c}435.6 \mu \mathrm{V} \\
894.8 \mu \mathrm{V} \\
1799.2 \mu \mathrm{V}\end{array}$ & $\begin{array}{c}519.4 \mu \mathrm{V} \\
1055.6 \mu \mathrm{V} \\
2135.5 \mu \mathrm{V}\end{array}$ \\
\hline \multicolumn{3}{|c|}{$\begin{array}{c}\text { TABLE VIII } \\
\text { 3D FEM - WITH A SHIELD }\end{array}$} \\
\hline $\begin{array}{c}120 \mathrm{~Hz} \text { and } \\
1200 \mathrm{rpm}, \mu_{\mathrm{r}-\mathrm{s}}=1000\end{array}$ & Only Iron & With copper \\
\hline $\begin{array}{c}\mu_{\mathrm{r}-\mathrm{i}}=75 \\
\mu_{\mathrm{r}-\mathrm{i}}=100 \\
\mu_{\mathrm{r}-\mathrm{i}}=125\end{array}$ & $\begin{array}{c}1171.7 \mu \mathrm{V} \\
1070.6 \mu \mathrm{V} \\
994.6 \mu \mathrm{V}\end{array}$ & $\begin{array}{l}1847.7 \mu \mathrm{V} \\
1799.2 \mu \mathrm{V} \\
1760.0 \mu \mathrm{V}\end{array}$ \\
\hline \multicolumn{3}{|c|}{$\begin{array}{c}\text { TABLE IX } \\
\text { 3D FEM - ONLY IRON AND WITH A SHIELD }\end{array}$} \\
\hline $\begin{array}{l}\text { Shield thickness and } \\
\text { relative permeability }\end{array}$ & & $\begin{array}{c}120 \mathrm{~Hz} \\
1200 \mathrm{rpm}\end{array}$ \\
\hline $\begin{array}{c}0.5 \mathrm{~mm}, \mu_{\mathrm{r}-\mathrm{s}}=1000 \\
0.5 \mathrm{~mm}, \mu_{\mathrm{r}-\mathrm{s}}=2000 \\
0.1 \mathrm{~mm}, \mu_{\mathrm{r}-\mathrm{s}}=10000 \\
0.1 \mathrm{~mm}, \mu_{\mathrm{r}-\mathrm{s}}=20000\end{array}$ & & $\begin{array}{l}1069.9 \mu \mathrm{V} \\
1251.6 \mu \mathrm{V} \\
1274.6 \mu \mathrm{V} \\
1366.8 \mu \mathrm{V}\end{array}$ \\
\hline
\end{tabular}

\section{An Aluminum Rod}

Fig. 13 shows the real, imaginary and absolute components of differential voltage versus speed for a rotating aluminumrod. Table $\mathrm{X}$ presents the parameters of the linear curve fitting according to (2). The induced voltage is considerably higher in the aluminum rod than in the iron rod because of the greater magnetic flux penetration depth and the greater skin depth [37]. The sensitivity coefficients $K$ in (2) are about $0.5 \mu \mathrm{V} / \mathrm{rpm}$ at $120 \mathrm{~Hz}$ and $0.54 \mu \mathrm{V} / \mathrm{rpm}$ at $180 \mathrm{~Hz}$ for an aluminumrod, while the sensitivity coefficients for the only iron rod are $0.13 \mu \mathrm{V} / \mathrm{rpm}$ at $120 \mathrm{~Hz}$ and $0.16 \mu \mathrm{V} / \mathrm{rpm}$ at $180 \mathrm{~Hz}$. The linearity errors for the only aluminum rod show higher nonlinearity in the imaginary component of the induced voltage, as in the case of the iron rod.

TABLE $X$

Linear Curve Parameters Fitted to The Measurements

\begin{tabular}{ccc}
\hline \hline Case & $K(n \mathrm{~V} / \mathrm{rpm})$ & $U_{\text {offset }}(n \mathrm{~V})$ \\
& $120 \mathrm{~Hz} / 180 \mathrm{~Hz}$ & $120 \mathrm{~Hz} / 180 \mathrm{~Hz}$ \\
\hline Only aluminum - Re & $-496.65 /-403.3$ & $-7333 /-14292$ \\
Only aluminum - Im & $63.63 / 354.03$ & $108850 / 163040$ \\
Only aluminum - Abs & $500.72 / 536.65$ & 0 \\
\hline \hline
\end{tabular}

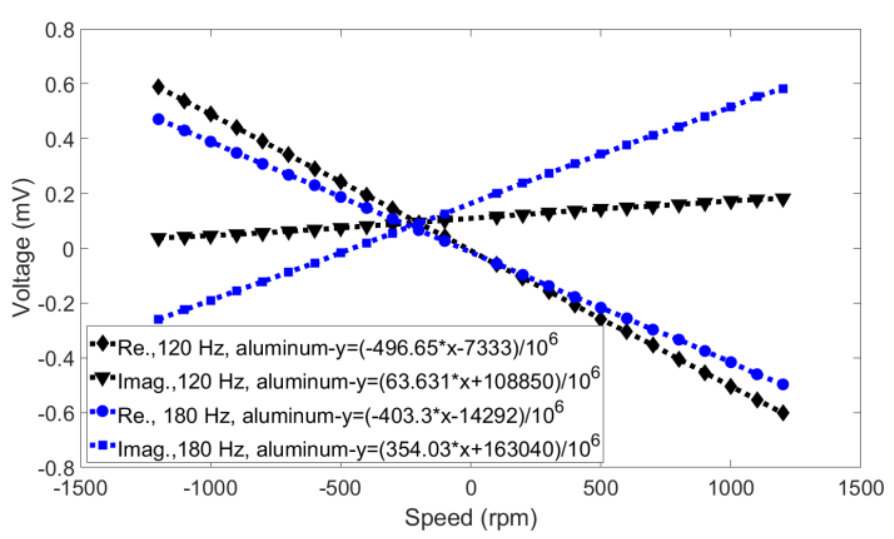

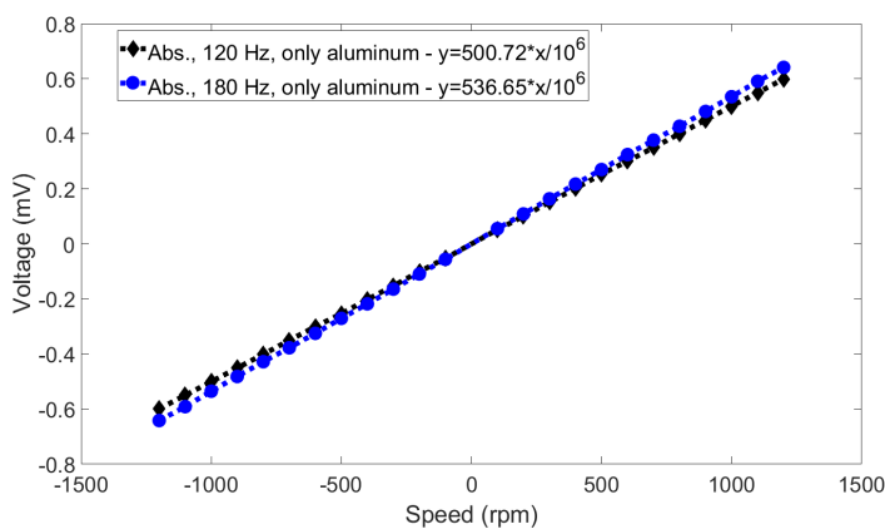

Fig. 13. Differential induced voltage (rms) caused by the rotating rod speed for an only aluminum rod, a) real and imaginary components of the voltage (top) and b) the absolute voltage value (bottom) - experimental results

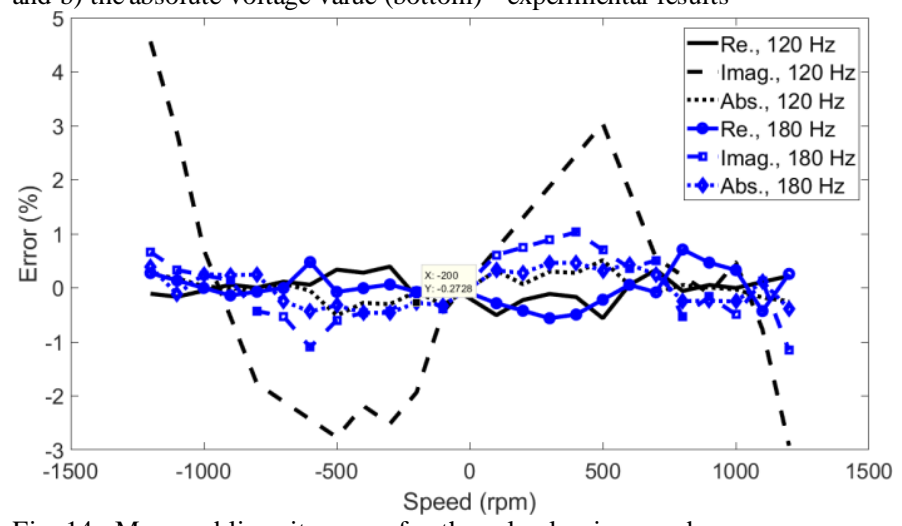

Fig. 14. Measured linearity errors for the only aluminum rod

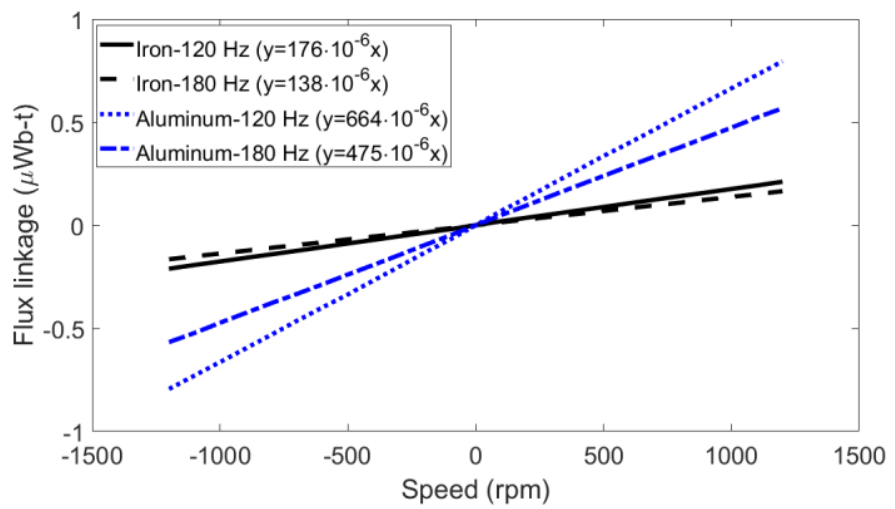

Fig. 15. Differential flux linkage variation versus speed for the only iron rod and for the only aluminum rod

A comparison between the 3D FEM results and the experimental results is presented in Table XI, which depicts higher matching than in the results for the only iron rod. The meas ured conductivity of the aluminumrod is $21.5 \mathrm{MS} / \mathrm{m}$. The effects of the material properties of the aluminum rod on the eddy current speed sensor are limited to the electrical conductivity, which is easier to compensate than in the case of iron rods with two properties, magnetic permeability and electrical conductivity.

TABLE XI

A COMPARISON BETWEEN MEASUREMENTS AND 3D FEM - ONLY ALUMINUM AND WITHOUT A SHIELD

$120 \mathrm{~Hz}$

$180 \mathrm{~Hz}$

3D FEM / EXP 


\begin{tabular}{ccc}
\hline $600 \mathrm{rpm}$ & $288.0 / 300.7 \mu \mathrm{V}$ & $305.3 / 324.8 \mu \mathrm{V}$ \\
$1200 \mathrm{rpm}$ & $574.9 / 599.4 \mu \mathrm{V}$ & $612.2 / 641.5 \mu \mathrm{V}$ \\
\hline \hline
\end{tabular}

\section{DISCUSSION}

Compensating the effects of material properties and temperature on the material properties of a conductive rotating rod is a key issue in the final design of an eddy current speed sens or for ind ustrial applications. Recent non-destructive s mart methods for estimating electrical conductivity and relative magnetic permeability using multi-frequency and phase signature techniques could be utilized for eddy current speed sens ors [38]-[40]. However, this topic lies beyond the scope of this paper. The temperature of rotating rod is critical factor on the sensor performance as electrical conductivity and magnetic permeability of rotating rod are changing with temperature [49]. For example, $10 \%$ conductivity decreasing of the iron rod causes $4 \%$ reduction in sensor sensitivity (Table V) and $25 \%$ permeability increasing causes $7 \%$ reduction in sensor sensitivity (Table VIII). The self heating of coil is negligible as the power consumption in the excitation coil of the proposed speed sensor is less than $0.2 \mathrm{~W}$.

The eddy current speed sensor proposed in this paper could also be used as a non-destructive method for making azimuthal vibration measurements. Measurements are made of the perpendicular vibrations and movements [41], and this is a convenient method.

The proposed speed sensor theoretically does not have maximum speed constraints. Only linearity of eddy current speed sensor could limit applicable maximum speed range. It is suggested to use higher operating frequency for higher speed ranges to keep sensor linearity error as low as possible as shown for absolute values of induced voltage at $120 \mathrm{~Hz}$ in comparison with $180 \mathrm{~Hz}$ in Fig. 9 and Fig. 10. The minimum measurable speed and sensor sensitivity depends on rod material, number of turns and configuration of coils and specially sensitivity of the used lock in amplifier. Minimum measurable speed can be achieved less than $0.1 \mathrm{rpm}$ in the proposed eddy current sensor with lock in amplifier used in this paper with minimum sensitivity $2 \mathrm{nV}$. The capability of reducing offset and noise are the most also important factors to reduce minimum measurable speed. Selection of operating frequency depends on the maximum sensitivity, minimum linearity error and fast dynamic response of speed sensor. The result show that higher excitation frequencies cause higher sensitivity and relatively higher linearity. However rod surface imperfectionscan deteriorate sensor performance as flux concentrate more close to the rod surface and it is more sensitive to non-visible small cracks. Therefore a compromise is required to select optimum frequency for a speed range.

It is clear that increasing the excitation frequency decreases the differential flux linkages of pick-up coils due to smaller magnetic flux penetration (Fig. 15). However, the induced differential voltage and therefore the sensitivity increases with the frequency, as the induced voltage is proportional to the multiple of the flux linkage and the frequency. Operating an eddy current speed sensor at higher frequencies is an efficient method for obtaining greater sensitivity. However, the skin depth is smaller at high frequency. Surface cracks and corrosion on the conductive rod could have a greater effect on the performance of eddy current speed sen sors at high frequencies if the radial thickness of the cracks or the corrosion depth is considerable in comparison with the magnetic flux penetration depth. Even small crack on the conductive rotating rod could cause accuracy error and noise in the speed sensor output [23] as eddy current speed sensor is sensitive to the rotating rod surface smoothness. Using copper coating can minimize the effect of cracks in the solid rotating rod.

The commercial magnetic speed sensor with tachometer configuration reports $1 \%$ linearity error [45], which is higher that maximum linearity error of the speed sensor proposed in this paper, which is $0.5 \%$. The maximum achievable resolution is $4.0 \mathrm{rpm}$.

Modeling and analyzing the eddy current speed sensor forms an important part of this paper, as it helps to analyze its performance and to optimize its parameters. The exact model for analys is should be three-dimensional, because the exact 3D distribution of the induced eddy currents is considered. A numerical method such as 3D FEM [48] is the first option, but it suffers from numerical errors, which are caused by insufficient mesh density, the motion of the rotating rod, and inadequate time steps. Increasing the mesh density and decreasing the time step could be a solution, but the simulation time will increase drastically, especially for a 3D model with eddy current effects in the solid conductive parts. The optimum solution is to develop an analytical model (appendix A). The equations in appendix A are extracted from Maxwell equations as 3D FEM, but they are simplified to solve analytically.

The equivalent circuit of antis erially connected pick up coils including self capacitance and capacitance between coil and ground and conductive rod are shown in Fig. 16. Equation (3) represents relationship between internal induced voltage and output voltage of the pick up coil. Output voltage is equal to internal voltage because capacitive reactance is very high in comparison with resistance and inductive reactance at low frequencies, $120 \mathrm{~Hz}$ and $180 \mathrm{~Hz}$ as shown in (3). The output voltage could be distorted at resonance frequency, which is much higher than $180 \mathrm{~Hz}$ used in this paper. For the case of our 100-turns pick up coils, the measured resistance, $R=15.4 \Omega$, inductance $L=15.45 \mathrm{mH}$ and self capacitance, $C_{c}-30.5 \mathrm{pF}$. The resonance frequency can be calculated equal to $f_{r}=$ $1 / 2 \pi / \sqrt{L C_{c}}=733 \mathrm{kHz}$

$$
\begin{gathered}
U_{o}=\frac{1}{j\left(C_{c}+C_{e} / 2\right) \omega} /\left(R+j \omega L+\frac{1}{j\left(C_{c}+C_{e} / 2\right) \omega}\right) U_{i} \\
\approx U_{i}, \omega=2 \pi f
\end{gathered}
$$

(3)

However, if we increase the number of turns of this coilin the attempt to increase the sensitivity, resonant frequency can be much lower.

Current to voltage converter could be used if resonance frequency is close to the operating frequency of eddy current speed sensor to avoid resonance effects on the sensor 
performance [48].

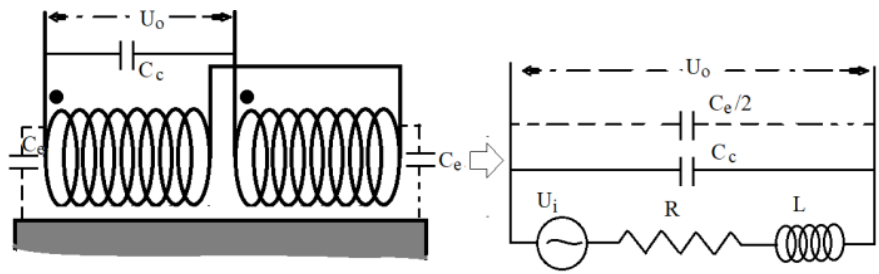

Fig. 16. Schematic model of pick up coils with self capacitance and capacitance between coil and ground and rod and its equivalent circuit

\section{CONCLUSION}

An eddy current sensor with a new structure for measuring the speed of a rotating rod has been presented. Various rotating rods with an only iron rod, with a copper-coated iron rod, and with an only aluminum rod have been considered in the measurements and in the analysis. The optimum angle of the coil span was obtained, i.e. $120 \mathrm{Deg}$, which is identical for an excitation coil and for pick-up coils. The tested eddy current speed sensor was manufactured with the optimum coil span angle.

The presented eddy current speed sensor is an appropriate selection for the speed measurements of any type of rotating machines, for example, turbines, motors, pumps, fans and turbochargers. For example, speed measurements for compact rotating electrical devices in electrical vehicles as the proposed eddy current speed sensor can beintegrated with rotating device and mounted on the shaft. This is advantage of this sensor, which does not need additional space at end shaft space dis similar to the conventionals peed sensor.

A simplified 1D analytical method has been developed for a general analysis of the eddy current speed sensor and for optimizing the sensor. An analytical method is used to facilitate rapid analy sis and rapid parametric calculations. The method is effective in terms of providing an analytical understanding of the performance of the eddy current speed sensor. 3D time stepping FEM, taking into account the rotating speed, was utilized for a detailed analysis and for further optimizations, including the effects of a magnetic yoke and a shield on the performance of the eddy current speed sensor. It has been shown that a magnetic yoke has a big influence on the sensitivity of the eddy current speed sensor. The use of a magnetic yoke can affect the linearity of the sensor. In addition, the magnetic properties of the yoke materials can be altered by ageing and by external fields. This is a drawback that should be taken into account in the design of the sensor.

The linearity error is lower, the sensitivity is considerably higher and the offset is lower for the real component of the induced voltage than for the imaginary component. The calculations indicate that the real component is also less sensitive to variations of the airgap. Using the experimental setup presented in this paper, we evaluated the linear error and made a comparison between the real and imaginary components of the induced voltage. The linearity error is about $0.5 \%$ and less, and this can be reduced by adjusting the experimental setup to avoid shaft vibrations of the prime mover.

A copper coating or any non-magnetic conductive coating is an effective method for increasing the sensitivity and reducing the effect of the magnetic permeability of solid iron. Selecting the optimum thickness of the non-magnetic conductive coating can drastically reduce the effect of the magnetic permeability of solid iron.

The real component of the induced voltage is more linear than the imaginary component of the induced voltage. It has als o been shown that the realcomponent of the induced voltage is less sensitive toeccentricity and to vibrations, as it is caused by induced eddy current los ses in the solid conductive rod.

Planned future work will be on compensating the temperature dependencies of the yoke properties, and on variations of the airgap.

\section{ACKNOWLEDGMENT}

The authors thank Mr. J. Cerny and Dr. J. Vyhnanek, from the Department of Measurement, Faculty of Electrical Engineering of the Czech Technical University for their support in building the rotationaleddy current speed sensor components and in preparing the measurementelements.

\section{APPENDIX A}

A 2D simplified computational model is presented to justify the performance the rotating eddy current speed sensor. Fig. A1 (a) shows the 2D computational model. For the sake of simplicity, only the magnetic fields in the air gap and the conductive non-magnetic coating are considered here. Therefore, the following assumptions are made:

1) It is assumed that the coils are shielded by a nonconductive (or laminated) magnetic material with infinite magnetic permeability.

2) The magnetic core of the rotor has the same properties as the magnetic shield.

3) Only the radial component of the magnetic flux density is considered in the modeling and in the simulations.

4) Only azimuthal variations $(\partial \theta)$ of the fields are considered, and radial variations $(\partial r)$ are set to zero.

5) Only the axial component of the induced eddy current (the $z$-axis) in the conductive coating is considered.

6) The source coils are modeled by two current sheets with infinitesimal thicknes s at angles of $-\theta_{\mathrm{e}}$ and $+\theta_{\mathrm{e}}$ (Fig. A1).

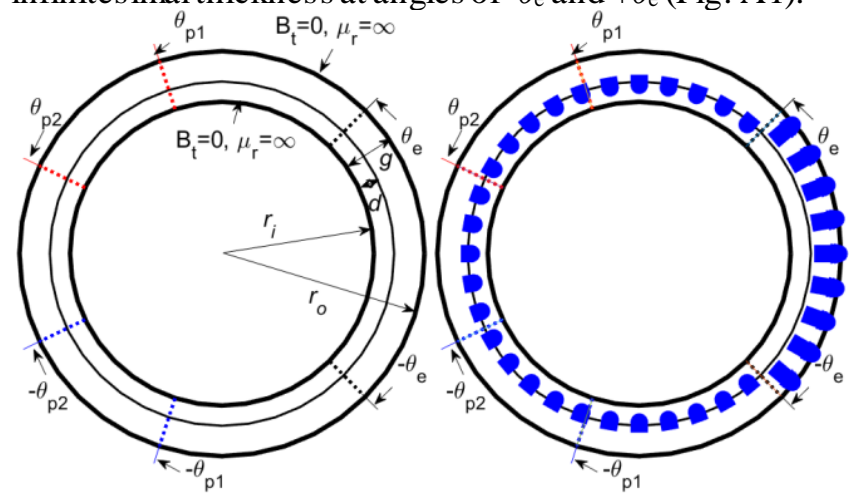




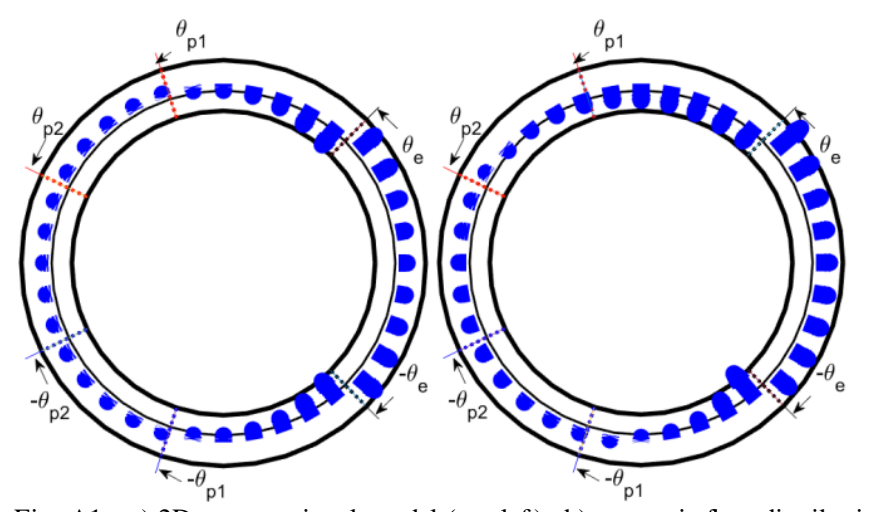

Fig. A1. a) 2D computational model (top-left), b) magnetic flux distribution for DC and zero speed (top-right), c) magnetic flux distribution for AC (100 $\mathrm{Hz})$ and zero speed (bottom-left), d) magnetic flux distribution for $\mathrm{AC}(100 \mathrm{~Hz})$ and nonzero speed (bottom-right),

7) Two pick-up coils are positioned at angles of $+\theta_{\mathrm{p} 1}$ and $+\theta_{\mathrm{p} 2}$ for pick-up coil 1 and at angles of $-\theta_{\mathrm{p} 1}$ and $-\theta_{\mathrm{p} 2}$ for pick-up coil 2.

The equations in (A1) can be derived using Ampere's law and Ohm's law, respectively [42]-[43]:

$$
\begin{gathered}
g \frac{\partial B_{r}}{\partial \theta}=-\mu_{0} \cdot J_{z} \cdot d \cdot r_{d}, \quad r_{d}=r_{i}+\frac{d}{2}, \quad g=r_{o}-r_{i} \\
\frac{1}{r_{d}} \frac{\partial J_{z}}{\partial \theta}=-\sigma\left(\frac{\partial B_{r}}{\partial \mathrm{t}}+\omega_{r} \frac{\partial B_{r}}{\partial \theta}\right), \quad \omega_{r}=2 \pi \frac{n_{r}}{60}
\end{gathered}
$$

where, $B_{\mathrm{r}}$, is the radial component of the flux density, $J_{\mathrm{z}}$ is the axial component of the induced eddy current in the conductive coating, $d$ is the radial thickness of the conductive coating, $r_{\mathrm{i}}$ is the inner radius of the conductive coating, $r_{\mathrm{o}}$ is the outer radius of the airg ap region, $n_{\mathrm{r}}$ is the rotational speed of the rotating part in rpm, and $f$ is the electrical frequency.

The induced eddy current has two components. First term, $\delta \mathrm{B}_{\mathrm{r}} / \delta \mathrm{t}$ and second term, $\omega_{\mathrm{r}} \cdot \delta \mathrm{B}_{\mathrm{r}} / \delta \theta$ in right side of equality in (A1) are transformer component caused by time variation of source field and motional (s peed) component, respectively [47]. The speed component of induced eddy current is linearly proportional to speed. Equation (A2) is extracted by substituting the first differential termin second differential term of (A1):

$$
\begin{gathered}
\frac{\partial^{2} B_{r}}{\partial \theta^{2}}-\omega_{r} \frac{d}{g} \mu_{0} \sigma r_{d}^{2} \frac{\partial B_{r}}{\partial \theta}-j \omega \frac{d}{g} \mu_{0} \sigma r_{d}^{2} B_{r}=0, \frac{\partial}{\partial t}=j \omega \\
\omega=2 \pi f
\end{gathered}
$$

The magnetic flux density has two components, $B_{\mathrm{r}}=B_{\mathrm{r}, \mathrm{s}}+B_{\mathrm{r}}$, r:

1) the source field caused by the source current sheets at angles of $-\theta_{\mathrm{e}}$ and $+\theta_{\mathrm{e}}: B_{\mathrm{r}, \mathrm{s}}$

2) the reaction field caused by the induced eddy current in the conductive coating: $B_{\mathrm{r}, \mathrm{r}}$

The source magnetic field, $B_{\mathrm{r}, \text { s }}$ can be written using Ampere's law and Gauss's law:
(A3)

$$
\begin{aligned}
& B_{r, s, 1}=\frac{\pi-\theta_{e}}{\pi} N_{e} I_{s} \frac{\mu_{0}}{g},-\theta_{e} \leq \theta \leq \theta_{e} \\
& B_{r, s, 2}=\frac{-\theta_{e}}{\pi} N_{e} I_{s} \frac{\mu_{0}}{g}, \theta \leq-\theta_{e}, \theta \geq \theta_{e}
\end{aligned}
$$

The Fourier series method is used to solve(A2) [35]-[37] and [44]. The source can therefore be written in Fourier series format in (A4), using (A3):

$$
\begin{gathered}
B_{r, s}=\sum_{\mathrm{n}= \pm 1, \pm 2, \cdots} C_{n} e^{j(\omega t-n \theta)} \\
C_{n}=\frac{1}{n \pi}\left(B_{r, s, 1}-B_{r, s, 2}\right) \sin \left(n \theta_{e}\right)
\end{gathered}
$$

Now the solution of (A2) is calculated as follows for the reaction field component of the magnetic fluxdensity, $B_{\mathrm{r}, \mathrm{r}}$ :

$$
\begin{aligned}
& B_{r, r}=\sum_{\mathrm{n}= \pm 1, \pm 2, \cdots} C_{n} C_{n}^{\prime} e^{j(\omega t-n \theta)} \\
& C_{n}^{\prime}=-j C_{n-1}^{\prime} \\
& /\left(n^{2}+j C_{n-1}^{\prime}\right), \quad C_{n-1}^{\prime} \\
& =\omega \frac{d}{g} \mu_{0} \sigma r_{d}^{2}-n \omega_{r} \frac{d}{g} \mu_{0} \sigma r_{d}^{2},
\end{aligned}
$$

The flux linkage $\lambda$ and the induced voltage $U$ of the pick-up coils on the left side and on the right side of the excitation coil are as follows:

$$
\begin{gathered}
\lambda_{l}=N_{p} r_{m} \sum_{\mathrm{n}= \pm 1, \pm 2, \cdots} \frac{C_{n}\left(1+C_{n}^{\prime}\right)}{-j n}\left(e^{-j n \theta_{p 2}}-e^{-j n \theta_{p 1}}\right) e^{j(\omega t)} \\
\lambda_{r}=N_{p} r_{m} \sum_{\mathrm{n}= \pm 1, \pm 2, \cdots} \frac{C_{n}\left(1+C_{n}^{\prime}\right)}{-j n}\left(e^{j n \theta_{p 1}}-e^{j n \theta_{p 2}}\right) e^{j(\omega t)} \\
U_{l}=-\frac{\partial \lambda_{l}}{\partial t}=-j \omega \lambda_{l}, U_{r}=-\frac{\partial \lambda_{r}}{\partial t}=-j \omega \lambda_{r}, \quad r_{m}=\frac{r_{o}+r_{i}}{2}
\end{gathered}
$$

The flux linkage difference, $\lambda_{\mathrm{d}}$ and the voltage difference, $U_{\mathrm{d}}$ between the left pick-up coil and the right pick-up coil are calculated:

(A7)

$$
\begin{aligned}
& \lambda_{d}=\lambda_{l}-\lambda_{r}=N_{p} r_{m} \sum_{\substack{n= \pm 1, \pm 2, \cdots \\
-j n}} \frac{2 C_{n} C_{n}^{\prime}}{-j n}\left(\cos \left(n \theta_{p 2}\right)\right. \\
& \left.-\cos \left(n \theta_{p 1}\right)\right) e^{j(\omega t)}
\end{aligned}
$$

$$
\begin{gathered}
U_{d}=-\frac{\partial \lambda_{d}}{\partial t}=-j \omega \lambda_{d}=\left(U_{d-r}+j U_{d-i}\right) e^{j(\omega t)} \\
U_{d-r} \\
=-\omega N_{p} r_{m} \sum_{\mathrm{n}= \pm 1, \pm 2, \cdots} \frac{2 C_{n} C_{n-1}^{\prime 2}}{n} \frac{\left(\cos \left(n \theta_{p 2}\right)-\cos \left(n \theta_{p 1}\right)\right)}{n^{4}+C_{n-1}^{\prime 2}}
\end{gathered}
$$




$$
\begin{aligned}
& U_{d-i} \\
& =-\omega N_{p} r_{m} \sum_{\mathrm{n}= \pm 1, \pm 2, \cdots} n^{2} \frac{2 C_{n} C_{n-1}^{\prime}}{n} \frac{\left(\cos \left(n \theta_{p 2}\right)-\cos \left(n \theta_{p 1}\right)\right)}{n^{4}+C_{n-1}^{\prime 2}}
\end{aligned}
$$

The voltage difference equation in (A8) depends on angles of $\theta_{\mathrm{p} 1}$ and $\theta_{\mathrm{p} 2}$, which shows effect of the mis alignments of pick up coils on the sensor performance. Also the effect of $g$ ap between rotating rod and coils, $g$ is considerable in the sensor performance as it affects the source field in (A3) and reaction fields in (A5). Fig. A1 b), c) and d) shows the magnetic flux density dis tribution in vector form for different electric sources (DC and AC) and speeds. It is obvious that the speed effect causes the flux linkages in the pick-up coil on the left side and the pick-up coil on the right side to diverge from each other. The voltages and flux linkages of two pick up coils diverge from each other and their voltage and flux linkage difference increases as the speed increases (Fig. A2). The flux linkage decreases with increasing frequency because reaction fields of transformer component of induced eddy current are stronger at higher frequencies.
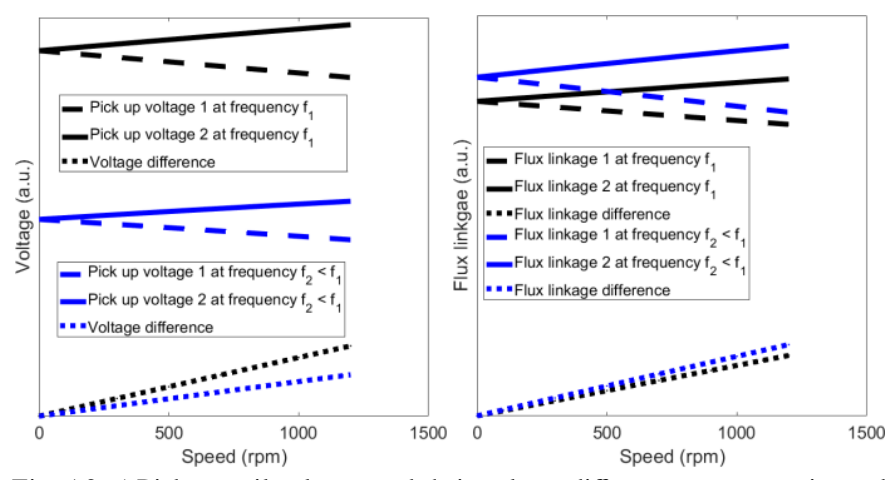

Fig. A2. a) Pick-up coil voltages and their voltage difference versus rotating rod speed (left) b) flux linkage variations versus rotating rod speed (right) -

\section{REFERENCES}

[1] M. Novak and J. Novak, "Test setup with a permanent magnet synchronous machine for efficiency maps of an electric vehicle," XIII Int. Conf. on Elec. Machines (ICEM), pp. 1698-1703, 2018

[2] H. Chen, W. Yan, J. J. Gu , and M. Su, "Multiobjective optimization design of a switched reluctance motor for low-speed electric vehicles with a Taguchi-CSO algorithm," IEEE/ASME Trans. Mechatronics, vol. 23, no. 4, pp. 1762-1774, August 2018

[3] M.-S. Lim, J.-M. Kim, Y.-S. Hwang, and J.-P. Hong, "Design ofan ultrahigh-speed permanent-magnet motor for an electric turbocharger considering speed response characteristics," IEEE/ASME Trans. Mechatronics, vol. 22, no. 2, pp. 774-784, Apr. 2017.

[4] Y. J. Oh, H.-C. Liu, S. Cho, J. H. Won, H. Lee, and Ju Lee, "Design, modeling, and analysis of a railway traction motor with independently rotating wheelsets," IEEE Trans. Magn., vol. 54, no. 11, 8205305, November 2018

[5] D.-K. Hong, T.-W. Lee, and Y.-H. Jeong, "Design and experimental validation of a high-speed electric turbocharger motor considering variation of the L/D ratio," IEEE Trans. Magn., vol. 54, no. 11, 2801904, November 2018

[6] S.S. Kalsi, J.G. Storey, K.A. Hamilton, R.A. Badcock, "Propulsion motor concepts for airplane," 2019 AIAA/IEEE Electric Aircraft Technologies Symposium (EATS), 2019

[7] Y. Terao, A. Seta, H. Ohsaki, H. Oyori, and N. Moriok, "Lightweight design of fully superconducting motors for electrical aircraft propulsion systems," IEEE Trans. on Applied Superconductivity, vol. 29, no. 5, 5202305, August 2019

[8] S. S. Kalsi, "Superconducting wind turbine generator employing MgB2 windings both on rotor and stator," IEEE Trans. on Applied Superconductivity, vol. 24, no. 1, 5201907, February 2014

[9] X. Wu, S. Huang, K. Liu, K. Lu, Y. Hu, W. Pan, and X. Peng, "Enhanoed position sensorless control using bilinear recursive least squares adaptive filter for interior permanent magnet synchronous motor," IEEE Trans. on Power Electronics, vol. 35, no. 1, pp. 681-698,January 2020

[10] Z. Xu, T. Zhang, Y. Bao, H. Zhang, and C. Gerada, "A nonlinear extended state observer for rotor position and speed estimation for sensorless IPMSM drives," IEEE Trans. on Power Electronics, vol. 35, no. 1, pp. 733-743,January 2020

[11] P. Ripka, Magnetic Sensors and Magnetometers, Artech House, Jan. 1,2001

[12] X. Liu, C. Liu, and P. W. T. Pong, "Velocity measurement technique for permanent magnet synchronous motors through external stray magnetic field sensing," IEEE Sensors J., vol. 18, no. 10, pp. 4013-4021, May 15, 2018

[13] G. Liu, B. Chen, and X. Song, "High-precision speed and position estimation based on Hall vector frequency tracking for PMSM with bipolar Hall-effect sensors," IEEE Sensors J., vol. 19, no. 6, pp.23472355, March 15, 2019

[14] V. Petrucha and P. Ripka, "Rotational speed measurement and angular position reference for a cryogenic propellant electric pump," J. of Elec. Eng., vol. 66, no. 7/s, pp. 199-202, 2015

[15] J. Rickman, "Eddy current turbocharger blade speed detection," IEEE Trans. Magn., vol. MAG-18, no. 5, pp. 1014-1021, Sep. 1982

[16] T. Addabbo, M. Di Marco, A. Fort, E. Landi, M. Mugnaini, V. Vignoli, and G. Ferretti, "Instantaneous rotation speed measurement system based on variable reluctance sensors for torsional vibration monitoring," IEEE Trans. Instrum. Meas., vol. 68, no. 7, pp. 2363-2373, July 2019

[17] J. O. Manyala, T. Fritz, and M. Z. Atashbar, "Gearbox speed sensor design and performance optimization," IEEE Sensors J., vol. 13, no. 2, pp. 629636, February 2013

[18] W. Li, Z. Hua, W. Qian, L. Jianxuan, T. Jian, "Some considerations of eddy current proximity sensor applied for motor speed measurement," Int. Conf. on Elec. Machines and Systems, 2008

[19] L. Li, H. Hu, Y. Qin, and K. Tang, "Digital approach to rotational speed measurement using an electrostatic sensor," Sensors (Basel), vol. 19, no. 11, 2540, 2019

[20] C. Wu, C. Fan and G. Wen, "Self-powered speed sensor for turbodrills based on triboelectric nanogenerator," Sensors, vol. 19, no. 22, 4889, 2019

[21] D. Gonen, S. Stricker, "Analysis of an eddy-current brake," IEEE Trans. on Power App.\& Syst., vol. 84, no. 5, pp. 357-361, 1965

[22] S. Cho, H.-C. Liu, H. Ahn, J. Lee, and H.-W. Lee, "Eddy current brake with a two-layer structure: calculation and characterization of braking performance," IEEE Trans. on Mag., vol. 53, no. 11, 8110205, November 2017

[23] T. J. Rocha, H. G. Ramos, A. L. Ribeiro, and D. J. Pasadas, "Evaluation of subsurface defects using diffusion of motion-induced eddy currents," IEEE Trans. Instrum. Meas., vol. 65, no. 5, pp. 1182-1187, May 2016

[24] T. Itaya, K. Ishida, A. Tanaka, N. Takehira, and T. Miki, “Analysis of a fork-shaped rectangular coil oriented perpendicular to moving conductor slabs," NDT\& E International, 44, 413-420, 2011

[25] J.A. Shercliff, The Theory of Electromagnetic Flow Measurement, Cambridge University Press, 1962.

[26] T. Sonoda, R. Ueda, K. Fujitani, T. Irisa, and S. Tatata, "DC magnetic field type eddy current speed sensor detecting cross magnetization field with amorphous core," IEEE Trans. Magn., vol. MAG-21, no. 5, pp. 1732-1734, Sep. 1985

[27] C. Gong, A. Tuysuz, M. Flankl, T. Stolz, J. Kolar, T. Habetler, "Experimental analysis and optimization of a contactless eddy-currentbased speed sensor for smooth conductive surfaces," IEEE Trans. on Industrial Electronics, Early Access, 2019

[28] E. Cardelli, A. Faba, and F. Tissi, "Contact-less speed probe based on eddy currents," IEEE Trans. Magn., vol. 49, no. 7, pp. 3897-3900, Jul. 2013.

[29] N. Takehira, andA. Tanaka, "Analysis of a perpendicular-type eddycurrent speed meter," IEE Proc. A - Phys. Science, Meas. and Instr., Manag. and Educ.- Rev. , vol. 135, no. 2, pp. 89 - 94, Feb. 1988

[30] T. Itaya, K. Ishida, A. Tanaka, N. Takehira, and T. Miki, "Eddy current distribution for a rectangular coil arranged parallel to a moving conductor slab," IET Science, Meas. \& Tech., vol. 6, no. 2, pp. 43 - 51, Mar. 2012 
[31] T. Itaya, K. Ishida, A. Tanaka, and N. Takehira, "Analysis of a forkshaped rectangular coil facing moving sheet conductors," IET Science, Meas. \& Tech. , vol. 3 , no. 4, pp. 279 - 285, Jul. 2009

[32] T. Itaya, K. Ishida, Y. Kubota, A. T anaka, and N. Takehira, "Visualization of eddy current distributions for arbitrarily shaped coils parallel to a moving conductor slab," Prog. In Electromag. Research M, Vol. 47, 112,2016

[33] T. Itaya, K. Ishida, A. Tanaka, and N. Takehira, "Analysis of an eddy current speed meter by rectangular coil system," IEEJ Trans. on Fund. and Mat. 133(8),416-423 , January 2013

[34] A. Tuysuz, M. Flankl, J. W. Kolar, and A. Mutze, "Eddy-current-based contactless speed sensing of conductive surfaces," IEEE 2nd Annual Southern Power Electronics Conf. (SPEC), pp. 1 - 6, Dec. 2016

[35] M. Mirzaei, P. Ripka, A. Chirtsov, and J. Vyhnanek, "Eddy current linear speed sensor," IEEE Trans. Mag., vol. 55, no. 1, pp. 1-4, 2019

[36] M. Mirzaei, P. Ripka, J. Vyhnanek, A. Chirtsov and V. Grim, "Rotational eddy current speed sensor," IEEE Trans. Mag., vol. 55, no. 9, 4003710, September 2019

[37] M. Mirzaei, P. Ripka, A. Chirtsov, J. Vyhnanek, and V. Grim, "Design and modeling of a linear speed sensor with a flat type structure and air coils," J. of Magnetism and Magnetic Materials, vol. 495, 165834, 2020

[38] M. Lu, Y. Xie, W. Zhu, A. Peyton, W. Yin, "Determination of the magnetic permeability, electrical conductivity, and thickness of ferrite metallic plates using a multifrequency electromagnetic sensing system," IEEE Trans. Ind. Inf., vol. 15, no. 7, pp. 4111-4119, 2019

[39] W. Yin, J. Tang, M. Lu, H. Xu, R. Huang, Q. Zhao, Z. Zhang, and A.Peyton, "An equivalent-effect phenomenon in eddy current nondestructive testing of thin structures," IEEE Sensors J., Early access, 2019

[40] M. Lu, R. Huang, W. Yin, Q. Zhao, and A. Peyton, "Measurement of permeability for ferrous metallic plates using a novel lift-off compensation technique on phase signature," IEEE Sensors J., vol. 19, no. 17, pp. 7440-7446, 2019

[41] X. Xue, Y. Dong, and X. Wu, "Motion induced eddy current sensor for non-intrusive vibration measurement," IEEE Sensors J., vol. 20, no. 2, pp. 735-744, 2020

[42] S. A. Nasar, and I. Boldea, Linear Motion Electric Machines, John Wiley \& Sons Inc; 1st Printing edition, August 1976

[43] C. H. Lee, C. Y. Chin, "A theoretical analysis of linear induction motors," IEEE Trans. Power App. \& Syst., vol. 98, no. 2, pp. 679-688, Mar. 1979

[44] M. N. O. Sadiku, Numerical Techniques in Electromagnetics with MATLAB, 2nd ed. Boca Raton, FL, USA: CRC Press, 2000.

[45] Handheld tachometer, contact type, https://www.onosokki.co.jp/English/hp e/whats new/Catalog/PDF/digit al_tachometers.pdf

[46] P. Kaspar, P. Ripka, "Induction Coils: voltage versus current output," Imeko World Congress, , vol. 5, pp. 55-60. 2000

[47] P. Hammond, Applied Electromagnetism, Pergamon Press Ltd, Headington Hill Hall, Oxford, 1971

[48] K. J. Binns, P. J. Lawrenson, and C. W. Trowbridge, The Analytical and Numerical Solution of Electric and Magnetic Fields. Wiley-Blackwell, 1992

[49] M. Mirzaei, P. Ripka, A. Chirtsov, and V. Grim, "Temperature stability of the transformer position transducer for pneumatic cylinder," $J$. of Magnetism and Magnetic Materials, vol. 503, 166636, 2020 